\title{
Characterization of rifampicin-resistant Mycobacterium tuberculosis in Taiwan
}

\author{
Hsing-Yu Hwang, Chung-Yu Chang, Lin-Li Chang, Shui-Feng Chang, \\ Ya-Hui Chang and Yi-Jing Chen
}

\begin{abstract}
Correspondence
Yi-Jing Chen

ichich@kmu.edu.tw
\end{abstract}

Received 14 August 2002

Accepted 28 October 2002
Department of Microbiology, School of Medicine, Kaohsiung Medical University, 100 Shih-Chuan 1st Road, Kaohsiung 807, Taiwan, ROC

\begin{abstract}
Sixty-three rifampicin-resistant $\left(\mathrm{Rifr}^{\mathrm{r}}\right)$ isolates of Mycobacterium tuberculosis from Kaohsiung, Taiwan, were analysed for mutations in the core region (69 bp, codons $511-533$ ) of the rpoB gene. Some $84.1 \%(53 / 63)$ of the resistant isolates showed mutations in this region, especially in codons $531(41.5 \%), 526(18.9 \%), 516(15.1 \%)$ and 533 (7.5\%). Five novel alleles of a total of 16 different types of mutations were identified in Rifr isolates. Ten Rifr isolates (15.9\%) exhibited no mutations in the core region of $r p o B$. Also, they did not show mutations in another $365 \mathrm{bp}$ fragment (codons 99-220) of rpoB. The agar proportion method was used to determine the relationship between the degree of rifampicin resistance and alterations in the core region of rpo $B$. The results revealed that the mean $\mathrm{MIC}$ was $92.38 \mu \mathrm{g} \mathrm{ml}^{-1}$ for the 53 isolates with a mutation in the core region, whereas the mean MIC of the other 10 isolates without mutations was only $24.8 \mu \mathrm{g} \mathrm{ml}^{-1}$. This indicates that the isolates with mutations in the core region had higher levels of resistance than those without mutations in this region. IS6110 restriction fragment length polymorphism (RFLP) was used

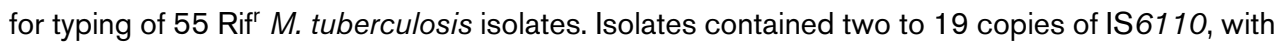
sizes ranging from 600 to $16000 \mathrm{bp}$. The majority (85\%) contained six to 16 copies. No strains lacking IS 6110 were found. A total of 54 of 55 RFLP types were defined at the $90 \%$ similarity level. The observation of varied IS6110-associated banding patterns indicates that an outbreak of drugresistant tuberculosis did not occur in this area.
\end{abstract}

\section{INTRODUCTION}

Among infectious diseases, tuberculosis (TB) is one of the most frequent causes of death in the world, with more than 2 million TB-related deaths reported each year (Dye et al., 1999). In 1997, an estimated 8 million new cases were reported and approximately 2 billion people, one third of the world's population, were infected with Mycobacterium tuberculosis (Dye et al., 1999). TB is one of the most important communicable diseases in Taiwan. It was the twelfth most common cause of death in 1998. The rates of incidence and mortality of TB per 100000 population were respectively 64.89 and 6.93 in the same year (Kan, 2000). In recent years, the control of $\mathrm{TB}$ has been impeded by the emergence of drug-resistant $M$. tuberculosis strains (Kan, 2000).

Rifampicin has proven to be an effective antituberculosis

Abbreviations: RFLP, restriction fragment length polymorphism; TB, tuberculosis; UPGMA, unweighted-pair group method using average linkage.

The GenBank/EMBL/DDBJ accession numbers for the sequences of the novel $M$. tuberculosis rpoB alleles found in this study are AF312232-AF312236. agent and its use has greatly shortened the duration of chemotherapy for the treatment of TB. Rifampicin resistance heralds higher rates of treatment failure and death for the patient and a poor outcome if the isolate is also resistant to isoniazid (Goble et al., 1993). The action of rifampicin is believed to interfere with transcription in bacteria by binding to the $\beta$ subunit of RNA polymerase (the product of the $r p o B$ gene) (Jin \& Gross, 1988). Mutations in certain highly conserved codons encoded by rpoB account for 'single step' high-level resistance to rifampicin in $M$. tuberculosis (Telenti et al., 1993). More than $90 \%$ of rifampicin-resistant (Rif $\left.{ }^{r}\right) M$. tuberculosis strains from different countries appear to harbour specific point mutations located in a 69-bp (core) region of $r p o B$ (codons 511-533) (Mani et al., 2001; Matsiota-Bernard et al., 1998; Ohno et al., 1996; Williams et al., 1998).

Since Rif ${ }^{\mathrm{r}}$ strains are a matter of great concern in Taiwan (Chiang et al., 1998; Wang \& Lin, 2001), it is of interest to study the molecular basis of rifampicin resistance in these local resistant isolates. One recent report concerned with the genotype of $r p o B$ of Rif $^{\mathrm{r}} M$. tuberculosis isolates from northern Taiwan reported four substitutions and one insertion (Qian et al., 2002). The mutation patterns among large 
numbers of isolates from Kaohsiung, in southern Taiwan, acquired in this work should allow a better understanding of any hot-spot regions on this gene for suitable rapid diagnosis and proper control of TB in Taiwan.

The correlation between the level of resistance to rifampicin and different mutational sites in the 69-bp core region of $r p o B$ seemed to vary in different regions (Mani et al., 2001; Williams et al., 1998; Ohno et al., 1997). Thus, the MICs of rifampicin for $\mathrm{Rif}^{\mathrm{r}}$ strains of $M$. tuberculosis with known alterations in $r p o B$ were determined.

Resistance to rifampicin has previously been associated with mutations in the early region of $r p o B$ in addition to mutations in the middle or end regions of this gene in Escherichia coli (Jin \& Gross, 1988; Lisitsyn et al., 1984). Recently, Heep et al. (2000) also reported a single, novel amino acid mutation at codon 149 in a clinical isolate of Helicobacter pylori that developed rifabutin resistance during therapy. A homologous mutation was also found in some $\operatorname{Rif}^{\mathrm{P}} M$. tuberculosis isolates with wild-type sequences in the 69-bp region (Heep et al., 2000). Therefore, isolates without mutations in the core region of the $r p o B$ gene were examined for potential mutations in the early part of $r p o B$.

The genetic polymorphism of $\operatorname{Rif}^{\top} M$. tuberculosis isolates was evaluated by IS6110 DNA fingerprinting (van Embden et al., 1993). The 1355-bp insertion sequence IS6110, belonging to the IS3 family of insertion elements of enterobacteria, has been found exclusively in members of the M. tuberculosis complex (Thierry et al., 1990). It is widely used as a probe for strain differentiation (Cave et al., 1991), confirming suspected cases of transmission (Edlin et al., 1992; Zaza et al., 1995), detection of laboratory contamination (Ramos et al., 1999; Dunlap et al., 1995) and distinguishing between exogenous re-infection or endogenous reactivation (Shafer et al., 1995; Small et al., 1993). In this work, we compared the RFLP patterns of Rif $^{\mathrm{r}} M$. tuberculosis isolates from patients in Kaohsiung by using IS6110 as a probe in order to examine the epidemiological relatedness of the isolates.

\section{METHODS}

M. tuberculosis strains. Clinical Rif isolates of M. tuberculosis were obtained from the Taiwan Provincial Kaohsiung Chronic Disease Prevention Center, the Kaohsiung Medical University Hospital and the Kaohsiung Chang Gung Memorial Hospital during 1996-1998, representing at least one-third of all cases in Kaohsiung. They were identified by conventional methods that included routine microscopy, culture and positive nitrate and niacin tests (Kent \& Kubica, 1985). The standard M. tuberculosis strains $\mathrm{H}_{37 \mathrm{Rv}^{\mathrm{T}}}$ (ATCC 27294 ${ }^{\mathrm{T}}$ ) and Mt.14323 (van Embden et al., 1993) and rifampicin-susceptible strains were employed as controls.

Drug-susceptibility testing. The test followed the modified agar proportion method using Middlebrook 7H10 agar plates to determine the susceptibility of $M$. tuberculosis clinical isolates (Kent \& Kubica, 1985; Inderlied \& Nash, 1996). The rifampicin concentration was $1.0 \mu \mathrm{g}$ $\mathrm{ml}^{-1}$. If the number of colonies that grew on the rifampicin-containing plate was $<1 \%$ of the number of colonies that grew on a drug-free medium, the isolate was defined as susceptible to rifampicin. The isolate was resistant if the number was $>1 \%$.
To determine the MIC of rifampicin of each isolate, serial twofold dilutions of rifampicin were incorporated in $7 \mathrm{H} 10$ agar at concentrations that ranged from 0 to $256 \mu \mathrm{g} \mathrm{ml}^{-1}$. Sets of quadrant Petri dishes (one quadrant in each plate contained drug-free medium) were inoculated with each isolate. Plates, tested in duplicate, were incubated at $37^{\circ} \mathrm{C}$ in the presence of $5 \% \mathrm{CO}_{2}$. Each plate was checked weekly and results were recorded after weeks 3 and 4 . The MIC was defined as the lowest concentration of drug that inhibited growth of the bacterial population by more than $99 \%$.

DNA extraction. Genomic DNA was extracted as described by van Soolingen et al. (1994) with modifications. Bacteria were harvested from the Löwenstein-Jensen slopes, heat-killed and incubated with lysozyme $\left(1 \mathrm{~h}, 37^{\circ} \mathrm{C}\right.$ ) followed by digestion with $50 \mu \mathrm{g}$ proteinase $\mathrm{K}$ in $10 \%$ SDS for $30 \mathrm{~min}$ at $65^{\circ} \mathrm{C}$. A further incubation with $\mathrm{CTAB} / \mathrm{NaCl}$ for $10 \mathrm{~min}$ at $65^{\circ} \mathrm{C}$ was followed by partition using chloroform/isoamyl alcohol $(24: 1, \mathrm{v} / \mathrm{v})$. Genomic DNA was extracted with phenol/chloroform and precipitated with $100 \%$ ethanol.

PCR amplification of mycobacterial strains. Aliquots of purified mycobacterial DNA (10-20 ng) were added to PCR reagents. The 157bp rрoB fragment (nt 1846-2002) was amplified by using the primers $\operatorname{Tr} 8$ (5'-TGCACGTCGCGGACCTCCA-3') and Tr9 (5'-TCGCC GCGATCAAGGAGT-3') as described previously (Telenti et al., 1993). To target a 365-bp fragment (early part) of $r p o B$ in $M$. tuberculosis, primers Tb176F (5'-CTTCTCCGGGTCGATGTCGTTG$\left.3^{\prime}\right)$ and Tb176R (5'-CGCGCTTGTCGACGTCAAACTC-3') were used (Heep et al., 2000).

Purification of PCR products and DNA sequencing. Template DNA was purified from the PCR products by using QIAquick PCR purification kit (Qiagen). Nucleotide sequencing was performed with the ABI PRISM Dye terminator cycle sequencing ready reaction kit (PerkinElmer) and the reactions were analysed on an ABI PRISM 373A DNA sequencer.

Restriction fragment length polymorphism (RFLP). Fifty-five Rif M. tuberculosis isolates were available for RFLP analysis. DNA fingerprinting was performed as described previously (van Embden et al., 1993; van Soolingen et al., 1994). Briefly, genomic DNA was digested with PvuII for $4-6$ h before being separated electrophoretically in a $1 \%$ agarose gel in $1 \times$ TBE running buffer at a constant voltage of $32 \mathrm{~V}$ for $16 \mathrm{~h}$. Next, the separated DNA fragments were transferred onto Hybond nylon membrane (Amersham). Hybridization was then performed using a digoxigenin-labelled 245-bp fragment of IS6110 $\left(25 \mathrm{ng} \mathrm{ml}^{-1}\right)$ as the DNA probe. Membranes were hybridized overnight under stringent conditions at $65^{\circ} \mathrm{C}$. Hybridized digoxigenin-labelled probe was detected with the DIG luminescent detection kit (Boehringer Mannheim) following the manufacturer's instructions.

As recommended previously (van Embden et al., 1993), PvuII-digested genomic DNA of M. tuberculosis reference strain Mt.14323 served as an external control of the hybridization conditions and a mixture of PvuIIdigested supercoiled DNA ladder and HaeIII-digested $\phi X 174$ DNA served as an internal marker.

Cluster analysis. DNA fingerprints were analysed by the GelCompar software (version 4.0; Applied Maths). A cluster was defined as two or more isolates with identical RFLP patterns when five or more copies of IS6110 were present. Autoradiograms were digitized by using a scanner with an optical resolution of 300 d.p.i. The sizes of IS6110 RFLP fragments were calculated by comparison of their mobilities with those of a set of internal markers of known molecular sizes (van Soolingen et al., 1994). The accuracy of the normalization procedure was controlled by comparing the IS6110 fingerprint patterns of reference strain M. tuberculosis Mt.14323. The fingerprint patterns were analysed for similarity by using the Dice coefficient and a dendrogram was 
calculated with the unweighted-pair group method using average linkage (UPGMA) according to the supplier's instructions. Band positions were determined by using the peak-finder function of the GelCompar software and were controlled manually by comparison with the original IS6110 autoradiogram.

Statistical analysis. The Mann-Whitney test was used for comparing mean MICs with the software package SPSS (SPSS Institute); $P<0.05$ was considered significant.

\section{RESULTS}

In this study, $63 \mathrm{Rif}^{\mathrm{r}}$ isolates and 12 rifampicin-sensitive $\left(\mathrm{Rif}^{\mathrm{s}}\right)$ clinical isolates were first examined for mutations in a 157-bp fragment of rpoB. Of $63 \mathrm{Rif}^{\mathrm{f}}$ isolates, $84 \cdot 1 \%(53 / 63)$ of the isolates showed mutations in this region. When compared with the published sequence, $15.9 \%(10 / 63)$ of the Rif ${ }^{\mathrm{r}}$ isolates and $12 \mathrm{Rif}^{\mathrm{s}}$ strains exhibited no mutations in this region. The most prevalent mutation sites were in codons $531(41.5 \%), 526(18.9 \%), 516(15 \cdot 1 \%)$ and 533 $(7 \cdot 5 \%)$ (Table 1$)$. The mutations found within the 69-bp core region of $r p o B$ in 53 of the resistant isolates are shown in Fig. 1.

A total of 16 different mutations and five novel alleles were identified within a 157-bp region of $r p o B$ of 53 Rif $^{\mathrm{r}}$ clinical isolates (Table 1; Fig. 1). Of the five novel alleles, one allele revealed changes of two bases in codon $516(\mathrm{GAC} \rightarrow \mathrm{TTC}$; Asp $\rightarrow$ Phe) and the other four alleles showed point mutations in two separate codons: codons 511 (CTG $\rightarrow$ CCG; Leu $\rightarrow$ Pro) and 516 (GAC $\rightarrow$ GGC; Asp $\rightarrow$ Gly); codons 526 $(\mathrm{CAC} \rightarrow \mathrm{TAC}$; His $\rightarrow \mathrm{Tyr})$ and $521(\mathrm{CTG} \rightarrow \mathrm{CTA}$; Leu $\rightarrow$ Leu $)$; codons 526 (CAC $\rightarrow$ CGC; His $\rightarrow$ Arg) and 529 (CGA $\rightarrow$ CAA; $\mathrm{Arg} \rightarrow \mathrm{Gln})$; and codons $516(\mathrm{GAC} \rightarrow \mathrm{AAC} ; \mathrm{Asp} \rightarrow \mathrm{Asn})$ and 533 (CTG $\rightarrow$ CCG; Leu $\rightarrow$ Pro) (Table 1).

The agar proportion method was used to understand the relationship between the degree of resistance to rifampicin and the mutation site. Growth of the 12 sensitive strains was inhibited at rifampicin concentrations $\leqslant 0 \cdot 25 \mu \mathrm{g} \mathrm{ml}^{-1}$, indicating the susceptibility of these strains. Isolates with mutations in the 69-bp core region of $r p o B$ were highly resistant to rifampicin, with MICs ranging from 8 to $256 \mu \mathrm{g} \mathrm{ml}^{-1}$, and the mean MIC was $92.38 \mu \mathrm{g} \mathrm{ml}^{-1}$ (Table 1). The MICs for the remaining 10 resistant isolates were between 2 and $128 \mu \mathrm{g}$ $\mathrm{ml}^{-1}$ and the mean MIC was $24 \cdot 8 \mu \mathrm{g} \mathrm{ml}^{-1}$. Our results revealed that strains with mutations in the 69-bp core region had significantly higher MICs than those without mutations in this region $(P<0 \cdot 05)$.

For the $10 \mathrm{Rif}^{\mathrm{r}}$ isolates without mutations in the 157-bp fragment, the possibility of mutations occurring in the early region (365-bp fragment) of $r p o B$ was then examined. PCRsingle-strand conformation polymorphism analysis and DNA sequencing exhibited patterns the same as that of $M$.

Table 1. Frequency of mutations in Rifr M. tuberculosis isolates and their levels of rifampicin susceptibility

\begin{tabular}{|c|c|c|c|}
\hline Mutated $\operatorname{codon}(s)$ & Specific mutation(s) & $n(\%)^{*}$ & $\operatorname{MIC}\left(\mu \mathrm{g} \mathrm{ml}^{-1}\right) \dagger$ \\
\hline \multicolumn{4}{|l|}{ Resistant } \\
\hline 531 & TCG(Ser) $\rightarrow$ TTG(Leu) & $22(41 \cdot 5)$ & $32(1), 64(9), 128(11), 256(1)$ \\
\hline \multirow{2}{*}{526} & $\mathrm{CAC}(\mathrm{His}) \rightarrow \mathrm{CGC}(\mathrm{Arg})$ & $2(3 \cdot 8)$ & 32 \\
\hline & $\mathrm{CAC}(\mathrm{His}) \rightarrow \mathrm{TAC}(\mathrm{Tyr})$ & $5(9 \cdot 4)$ & $32(1), 128(3), 256(1)$ \\
\hline 516 & $\mathrm{GAC}(\mathrm{Asp}) \rightarrow \mathrm{TTC}(\mathrm{Phe})$ & $2(3 \cdot 8)$ & 128 \\
\hline 533 & CTG(Leu) $\rightarrow$ CCG(Pro) & $4(7 \cdot 5)$ & $8(1), 64(2), 128(1)$ \\
\hline 511 & CTG(Leu) $\rightarrow$ CCG(Pro) & $1(1 \cdot 9)$ & 32 \\
\hline 522 & TCG(Ser) $\rightarrow$ TTG(Leu $)$ & $1(1 \cdot 9)$ & 8 \\
\hline 511,516 & CTG(Leu) $\rightarrow$ CCG(Pro), GAC(Asp) $\rightarrow$ GGC(Gly) $\ddagger$ & $2(3 \cdot 8)$ & 64 \\
\hline 516,533 & $\mathrm{GAC}($ Asp $) \rightarrow \mathrm{AAC}($ Asn $), \mathrm{CTG}(\mathrm{Leu}) \rightarrow \mathrm{CCG}($ Pro $) \downarrow$ & $1(1 \cdot 9)$ & 64 \\
\hline None & - & 10 & $2(2), 4(1), 8(2), 16(2), 32(2), 128(1)$ \\
\hline \multicolumn{4}{|l|}{ Susceptible } \\
\hline None & - & 12 & $<0.25$ \\
\hline
\end{tabular}

${ }^{\star}$ Percentages of isolates carrying mutations in the core region are given in parentheses.

$\dagger$ Where strains with the same mutation(s) gave different MIC values, the number of strains exhibiting each MIC is given in parentheses.

\$Novel pattern of substitution. 


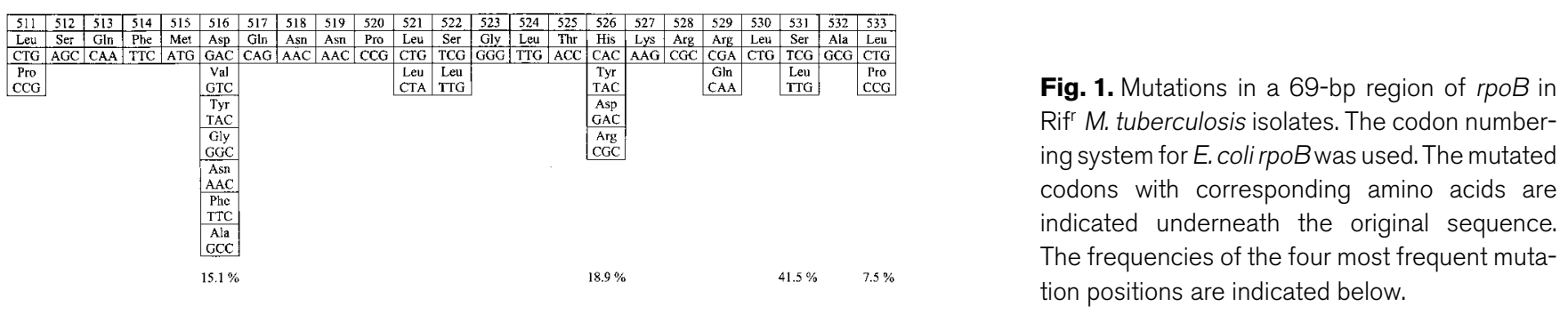

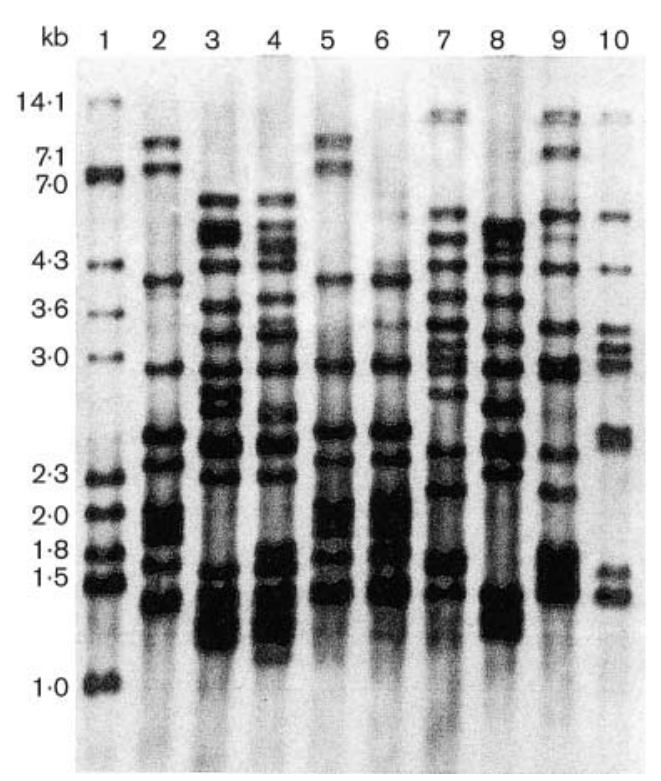

Fig. 2. IS6110-based RFLP patterns of nine Rifr $M$. tuberculosis isolates from patients. DNA was digested with the restriction enzyme Pvull. The probe was a 245-bp DNA fragment of IS6110. Lanes: 1, reference strain M. tuberculosis Mt.14323; 2-10, clinical M. tuberculosis isolates.

tuberculosis Mt.14323 (data not shown). These results demonstrated that these $10 \mathrm{Rif}^{\mathrm{r}}$ isolates did not show mutations in the 157-bp or 365-bp fragment of $r p o B$.

In this study, $55 \mathrm{Rif}^{\mathrm{r}} \mathrm{M}$. tuberculosis isolates were analysed by the standardized DNA fingerprinting method with IS6110 as a genetic marker. The IS6110 fingerprint patterns generated were highly variable (Fig. 2). The number of copies of IS6110 per isolate varied from two to 19 , with sizes ranging from 600 to $16000 \mathrm{bp}$. The majority of the 55 isolates $(85 \%)$, contained six to 16 copies, with a median of 10 bands (Fig. 3). No isolates lacking IS6110 were found.

The similarities of all 55 IS6110 fingerprint patterns were then analysed. A total of 54 of 55 RFLP types were defined at the $90 \%$ similarity level (Fig. 4). Two (C14 and C389) of 17 isolates with mutations in codon 531 had $95.5 \%$ similarity, with different drug-resistance patterns. Isolate $\mathrm{C} 14$ was susceptible to kanamycin and ethambutol, while C389 was resistant to both of these drugs. Close relatedness was not

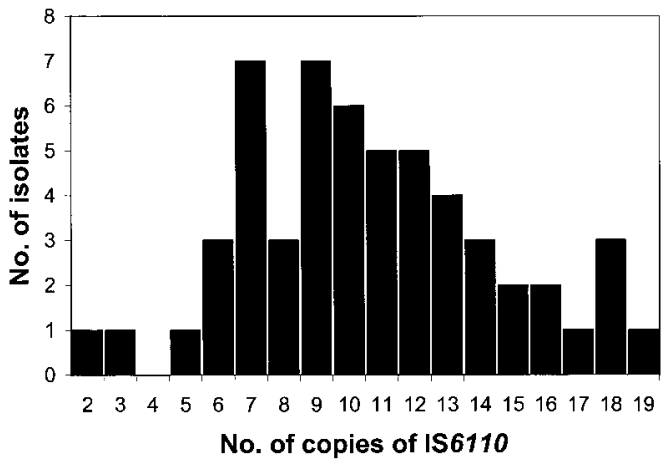

Fig. 3. Number of IS6110 copies in the DNA of 55 Rifr $^{r}$ M. tuberculosis isolates.

observed between other resistant isolates carrying mutations in either of the two other highly mutated sites, codons 526 and 516 (data not shown).

\section{DISCUSSION}

It was observed that the majority $(75.5 \%)$ of $\operatorname{Rif}^{\mathrm{P}} M$. tuberculosis isolates contained missense mutations that led to substitutions of amino acids at Ser-531 (41.5\%), His-526 $(18.9 \%)$ or Asp-516 (15.1\%) in the core region of rpoB. While codon 531 is the most common site of nucleotide substitutions worldwide, mutations at the other two prevalent sites (codons 526 and 516) in our strains occur at different frequencies in strains from other geographical regions (Qian et al., 2002; Pozzi et al., 1999; Taniguchi et al., 1996). Distinctly, about $8 \%$ of Rif ${ }^{\mathrm{f}} M$. tuberculosis isolates displayed point mutations in codon 533 in this study. However, this missense mutation in codon 533 only occurred at low frequency $(<3.3 \%)$ or no mutations at all were reported in other geographical regions (Mani et al., 2001; Pozzi et al., 1999; Bartfai et al., 2001; Valim et al., 2000). These differences may be attributed to geographical genetic differences in $\operatorname{Rif}^{r} M$. tuberculosis strains and the transmission of these strains among patients in different countries.

Unexpectedly, $10(15.9 \%)$ of the $63 \mathrm{Rif}^{\mathrm{r}}$ clinical isolates in this study showed no mutations in the sequenced 157-bp region of $r p o B$, despite the fact that these isolates were resistant to rifampicin. A comparable high frequency (20 $\% ; 4 / 20)$ of Rif isolates with no mutations in this core region was also reported recently from northern Taiwan (Qian et al., 


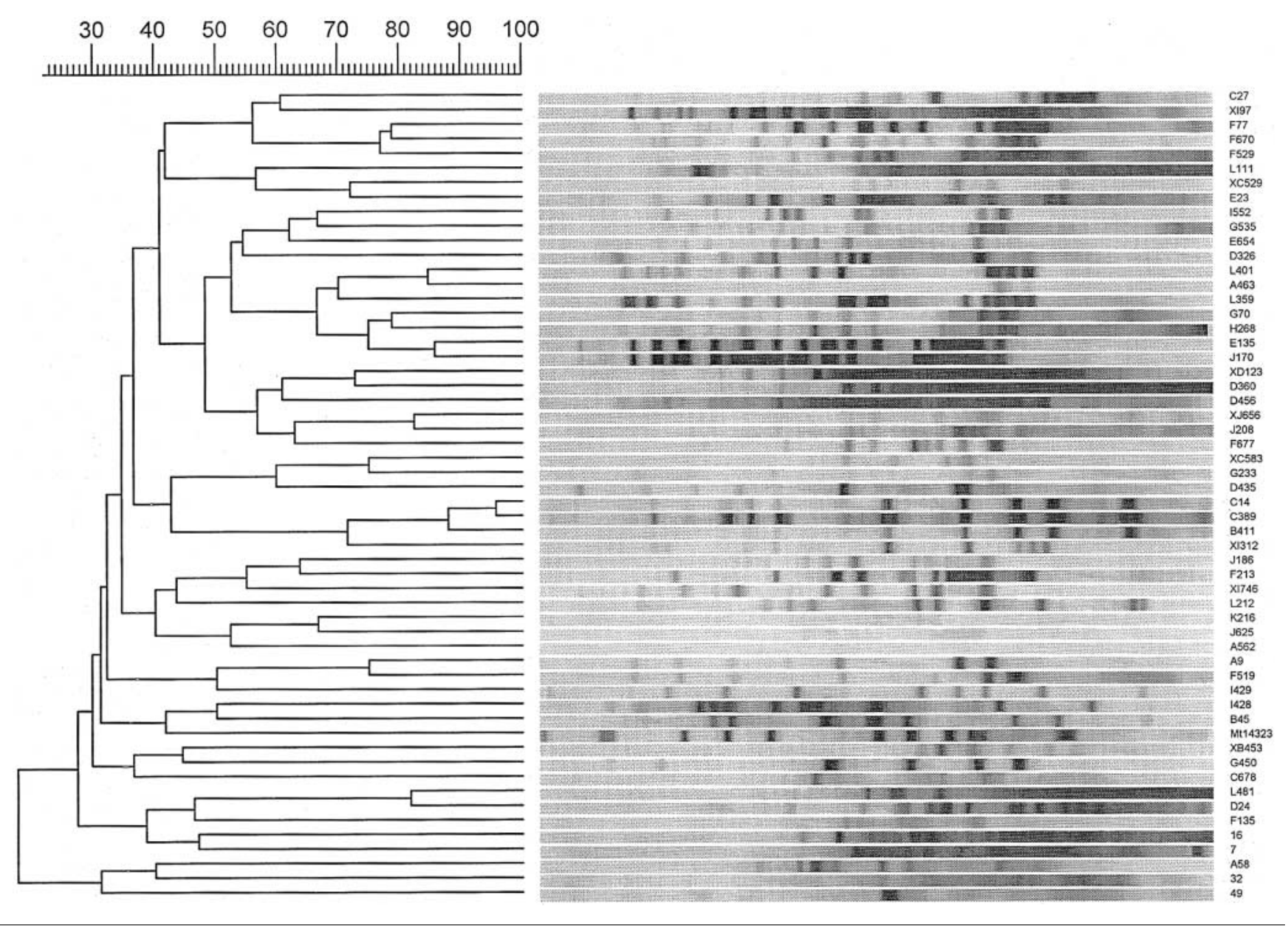

Fig. 4. Dendrogram of M. tuberculosis isolates $(n=55)$ by RFLP typing.

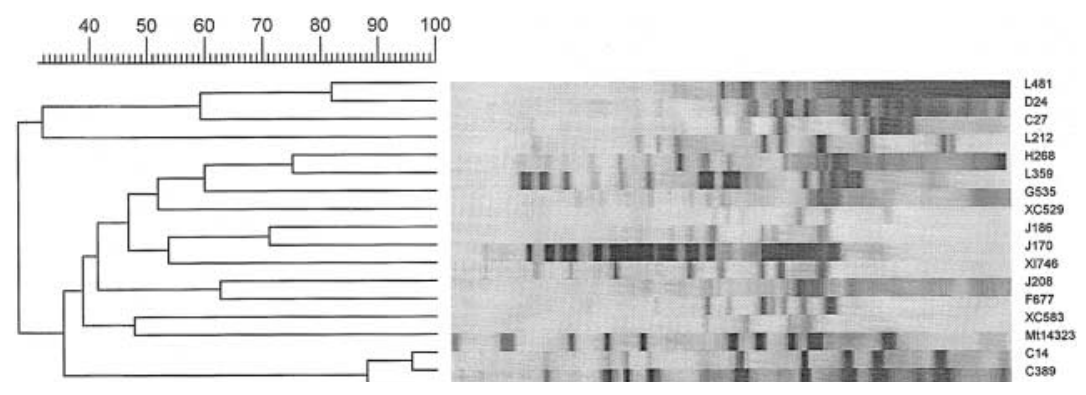

Fig. 5. Dendrogram of $M$. tuberculosis isolates with mutations in codon $531(n=17)$.

2002). The frequency is comparatively higher than those that have been reported for Rif ${ }^{\mathrm{r}}$ isolates from other geographical areas. More than $90 \%$ of Rif $^{\mathrm{r}}$ strains from other regions had mutations located in the 69-bp core region (Telenti et al., 1993; Mani et al., 2001; Matsiota-Bernard et al., 1998; Ohno et al., 1996; Williams et al., 1994). DNA sequencing of the early part of $r p o B$ in these $10 \mathrm{Rif}^{\mathrm{r}}$ isolates showed no mutations in a 365-bp region. This indicated the possible occurrence of an alteration outside the two regions of $r p o B$ examined, such as mutations in V176F (Heep et al., 2001) and codon 381 (Taniguchi et al., 1996). Among other explanations, several additional genes may be involved in rifampicin resistance. A change in the antibiotic permeability of a membrane or in metabolism could also give rise to the rifampicin-resistant phenotype (Hui et al., 1977; Konno et al., 1973).

In general, amino acid substitution in the 69-bp core region led to higher levels of resistance to rifampicin than those isolates without mutations in this region $(P<0 \cdot 05$, Table 1$)$. Some investigators have even demonstrated that different levels of resistance are associated with different mutational 
sites in this region (Ohno et al., 1996, 1997; Taniguchi et al., 1996). Thus, strains with mutations in either codon 531 or 526 were usually highly rifampicin-resistant, as revealed in this report and others (Ohno et al., 1996; Williams et al., 1998; Taniguchi et al., 1996). However, in contrast to previous findings on mutations in codon 533 (Ohno et al., 1996), our four isolates with amino acid substitution in this codon (Leu $\rightarrow$ Pro) did not show a consistently low level of resistance (MIC $<2 \mu \mathrm{g} \mathrm{ml} \mathrm{ml}^{-1}$ ). Likewise, high MICs $\left(>128 \mu \mathrm{g} \mathrm{ml}^{-1}\right)$ for isolates with mutations in codon 516 or 533 were also observed in India (Mani et al., 2001). Thus, the association between particular mutational sites on $r p o B$ and the drug susceptibility of multidrug-resistant M. tuberculosis strains is not apparent in some areas, including Taiwan. Noticeably, the same mutation in the same codon in the 69-bp region did not reflect the same level of drug resistance in these resistant isolates (Table 1; Ohno et al., 1996). Some other additional factor(s) might contribute to the variation in drug resistance (Hui et al., 1977; Konno et al., 1973). Thus, sequencing of $r p o B$ is not completely able to replace traditional methods of susceptibility testing to detect the level of rifampicin resistance of $M$. tuberculosis.

The results showed that $\operatorname{Rif}^{\mathrm{r}} M$. tuberculosis strains from this area were highly polymorphic. The majority of the TB cases were therefore presumed to be the result of re-activation of previously contracted $M$. tuberculosis infections. Furthermore, our results showed that most isolates, even with the same mutated codon, did not have similar patterns or locations of IS6110 copies (Fig. 5). This suggests that acquisition of rifampicin resistance followed the infection of a rifampicin-susceptible strain in this work. In contrast to a report from Cape Town, where most drug-resistant TB cases represented new infections (van Rie et al., 2000), our results did not reveal an outbreak of $\operatorname{Rif}^{\mathrm{r}} M$. tuberculosis strains in this area.

In conclusion, five novel alleles, as well as some universal prevailing mutations, in the core region of $r p o B$ were observed in our Rif ${ }^{\mathrm{r}} M$. tuberculosis isolates. The mutated codon might affect the MIC for rifampicin, although other additional factors might contribute to variation in drug resistance. Analysis of RFLP patterns of our Rif ${ }^{\mathrm{f}} M$. tuberculosis isolates suggested that latent re-activation rather than active transmission accounted for most TB cases. Nevertheless, we consider that the establishment of a DNA fingerprinting bank will be extremely helpful for tracing recent sources of infection, for the control of a possible spread of multidrug-resistant organisms and for the surveillance of TB in general.

\section{ACKNOWLEDGEMENTS}

This work was supported financially in part by grants from the Department of Health, Republic of China (DOH84-TD-053, DOH85TD-027) and Kaohsiung Medical University.

\section{REFERENCES}

Bartfai, Z., Somoskovi, A., Kodmon, C. \& 7 other authors (2001).
Molecular characterization of rifampin-resistant isolates of Mycobacterium tuberculosis from Hungary by DNA sequencing and the line probe assay. J Clin Microbiol 39, 3736-3739.

Cave, M. D., Eisenach, K. D., McDermott, P. F., Bates, J. H. \& Crawford, J. T. (1991). IS6110: conservation of sequence in the Mycobacterium tuberculosis complex and its utilization in DNA fingerprinting. Mol Cell Probes 5, 73-80.

Chiang, I. H., Yu, M. C., Bai, K. J., Wu, M. P., Hsu, C. J., Lin, T. P. \& Luh, K. T. (1998). Drug resistance patterns of tuberculosis in Taiwan. J Formos Med Assoc 97, 581-583.

Dunlap, N. E., Harris, R. H., Benjamin, W. H., Jr, Harden, J. W. \& Hafner, D. (1995). Laboratory contamination of Mycobacterium tuberculosis cultures. Am J Respir Crit Care Med 152, 1702-1704.

Dye, C., Scheele, S., Dolin, P., Pathania, V. \& Raviglione, M. C. (1999). Consensus statement. Global burden of tuberculosis: estimated incidence, prevalence, and mortality by country. WHO Global Surveillance and Monitoring Project. JAMA 282, 677-686.

Edlin, B. R., Tokars, J. I., Grieco, M. H. \& 9 other authors (1992). An outbreak of multidrug-resistant tuberculosis among hospitalized patients with the acquired immunodeficiency syndrome. $N$ Engl J Med 326, 1514-1521.

Goble, M., Iseman, M. D., Madsen, L. A., Waite, D., Ackerson, L. \& Horsburgh, C. R., Jr (1993). Treatment of 171 patients with pulmonary tuberculosis resistant to isoniazid and rifampin. $N$ Engl J Med 328, $527-532$

Heep, M., Rieger, U., Beck, D. \& Lehn, N. (2000). Mutations in the beginning of the $r p o B$ gene can induce resistance to rifamycins in both Helicobacter pylori and Mycobacterium tuberculosis. Antimicrob Agents Chemother 44, 1075-1077.

Heep, M., Brandstatter, B., Rieger, U., Lehn, N., Richter, E., RuschGerdes, S. \& Niemann, S. (2001). Frequency of $r p o B$ mutations inside and outside the cluster I region in rifampin-resistant clinical Mycobacterium tuberculosis isolates. J Clin Microbiol 39, 107-110.

Hui, J., Gordon, N. \& Kajioka, R. (1977). Permeability barrier to rifampin in mycobacteria. Antimicrob Agents Chemother 11, 773-779.

Inderlied, C. B. \& Nash, K. A. (1996). Antimycobacterial agents: in vitro susceptibility testing, spectra of activity, mechanisms of action and resistance, and assays for activity in biologic fluids. In Antibiotics in Laboratory Medicine, 4th edn, pp. 127-175. Edited by V. Lorian. Baltimore: Williams \& Wilkins.

Jin, D. J. \& Gross, C. A. (1988). Mapping and sequencing of mutations in the Escherichia coli rpoB gene that lead to rifampicin resistance. J Mol Biol 202, 45-58.

Kan, M. (2000). Current status of tuberculosis in Taiwan. Epidemiol Bull Cent Dis Control Dep Health ROC 16, 44-47.

Kent, P. T. \& Kubica, G. P. (1985). Public Health Mycobacteriology. A Guide for the Level III Laboratory. Atlanta: US Department of Health and Human Services, Centers for Disease Control and Prevention.

Konno, K., Oizumi, K. \& Oka, S. (1973). Mode of action of rifampin on mycobacteria. II. Biosynthetic studies on the inhibition of ribonucleic acid polymerase of Mycobacterium bovis BCG by rifampin and uptake of rifampin- ${ }^{14} \mathrm{C}$ by Mycobacterium phlei. Am Rev Respir Dis 107, $1006-1012$.

Lisitsyn, N. A., Sverdlov, E. D., Moiseyeva, E. P., Danilevskaya, O. N. \& Nikiforov, V. G. (1984). Mutation to rifampicin resistance at the beginning of the RNA polymerase beta subunit gene in Escherichia coli. Mol Gen Genet 196, 173-174.

Mani, C., Selvakumar, N., Narayanan, S. \& Narayanan, P. R. (2001). Mutations in the $r p o B$ gene of multidrug-resistant Mycobacterium tuberculosis clinical isolates from India. J Clin Microbiol 39, 2987-2990. 
Matsiota-Bernard, P., Vrioni, G. \& Marinis, E. (1998). Characterization of $r p o B$ mutations in rifampin-resistant clinical Mycobacterium tuberculosis isolates from Greece. J Clin Microbiol 36, 20-23.

Ohno, H., Koga, H., Kohno, S., Tashiro, T. \& Hara, K. (1996). Relationship between rifampin MICs for and $r p o B$ mutations of Mycobacterium tuberculosis strains isolated in Japan. Antimicrob Agents Chemother 40, 1053-1056.

Ohno, H., Koga, H., Kuroita, T. \& 7 other authors (1997). Rapid prediction of rifampin susceptibility of Mycobacterium tuberculosis. Am J Respir Crit Care Med 155, 2057-2063.

Pozzi, G., Meloni, M., Iona, E., Orru, G., Thoresen, O. F., Ricci, M. L., Oggioni, M. R., Fattorini, L. \& Orefici, G. (1999). rpoB mutations in multidrug-resistant strains of Mycobacterium tuberculosis isolated in Italy. J Clin Microbiol 37, 1197-1199.

Qian, L., Abe, C., Lin, T. P., Yu, M. C., Cho, S. N., Wang, S. \& Douglas, J. T. (2002). $r p o B$ genotypes of Mycobacterium tuberculosis Beijing family isolates from East Asian countries. J Clin Microbiol 40, 1091-1094.

Ramos, M. de C., Soini, H., Roscanni, G. C., Jaques, M., Villares, M. C. \& Musser, J. M. (1999). Extensive cross-contamination of specimens with Mycobacterium tuberculosis in a reference laboratory. J Clin Microbiol 37, 916-919.

Shafer, R. W., Singh, S. P., Larkin, C. \& Small, P. M. (1995). Exogenous reinfection with multidrug-resistant Mycobacterium tuberculosis in an immunocompetent patient. Tuber Lung Dis 76, 575-577.

Small, P. M., Shafer, R. W., Hopewell, P. C., Singh, S. P., Murphy, M. J., Desmond, E., Sierra, M. F. \& Schoolnik, G. K. (1993). Exogenous reinfection with multidrug-resistant Mycobacterium tuberculosis in patients with advanced HIV infection. N Engl J Med 328, 1137-1144.

Taniguchi, H., Aramaki, H., Nikaido, Y., Mizuguchi, Y., Nakamura, M., Koga, T. \& Yoshida, S. (1996). Rifampicin resistance and mutation of the rpoB gene in Mycobacterium tuberculosis. FEMS Microbiol Lett 144, 103-108.

Telenti, A., Imboden, P., Marchesi, F., Lowrie, D., Cole, S., Colston, M. J.,
Matter, L., Schopfer, K. \& Bodmer, T. (1993). Detection of rifampicinresistance mutations in Mycobacterium tuberculosis. Lancet 341, 647-650.

Thierry, D., Cave, M. D., Eisenach, K. D., Crawford, J. T., Bates, J. H., Gicquel, B. \& Guesdon, J. L. (1990). IS6110, an IS-like element of Mycobacterium tuberculosis complex. Nucleic Acids Res 18, 188.

Valim, A. R., Rossetti, M. L., Ribeiro, M. O. \& Zaha, A. (2000). Mutations in the $r p o B$ gene of multidrug-resistant Mycobacterium tuberculosis isolates from Brazil. J Clin Microbiol 38, 3119-3122.

van Embden, J. D., Cave, M. D., Crawford, J. T. \& 8 other authors (1993). Strain identification of Mycobacterium tuberculosis by DNA fingerprinting: recommendations for a standardized methodology. JClin Microbiol 31, 406-409.

van Rie, A., Warren, R., Richardson, M., Gie, R. P., Enarson, D. A., Beyers, N. \& Van Helden, P. D. (2000). Classification of drug-resistant tuberculosis in an epidemic area. Lancet 356, 22-25.

van Soolingen, D., de Haas, P. E., Hermans, P. W. \& van Embden, J. D. (1994). DNA fingerprinting of Mycobacterium tuberculosis. Methods Enzymol 235, 196-205.

Wang, P. D. \& Lin, R. S. (2001). Drug-resistant tuberculosis in Taipei, 1996-1999. Am J Infect Control 29, 41-47.

Williams, D. L., Waguespack, C., Eisenach, K. \& 7 other authors (1994). Characterization of rifampin-resistance in pathogenic mycobacteria. Antimicrob Agents Chemother 38, 2380-2386.

Williams, D. L., Spring, L., Collins, L., Miller, L. P., Heifets, L. B., Gangadharam, P. R. \& Gillis, T. P. (1998). Contribution of $r p o B$ mutations to development of rifamycin cross-resistance in Mycobacterium tuberculosis. Antimicrob Agents Chemother 42, 1853-1857.

Zaza, S., Blumberg, H. M., Beck-Sague, C. \& 7 other authors (1995). Nosocomial transmission of Mycobacterium tuberculosis: role of health care workers in outbreak propagation. J Infect Dis 172, 1542-1549. 